\title{
Tensile Deformation and Fracture Mechanism of Bulk Bimodal Ultrafine-Grained Al-Mg Alloy
}

\author{
ZONGHOON LEE, VELIMIR RADMILOVIC, BYUNGMIN AHN, \\ ENRIQUE J. LAVERNIA, and STEVEN R. NUTT
}

\begin{abstract}
The tensile fractures of ultrafine-grained (UFG) Al-Mg alloy with a bimodal grain size were investigated at the micro- and macroscale using transmission electron microscopy (TEM), scanning electron microscopy (SEM) equipped with focused ion beam (FIB), and optical microscopy. The nanoscale voids and crack behaviors near the tensile fracture surfaces were revealed in various scale ranges and provided the evidence to determine the underlying tensile deformation and fracture mechanisms associated with the bulk bimodal metals. The bimodal grain structures exhibit unusual deformation and fracture mechanisms similar to ductile-phase toughening of brittle materials. The ductile coarse grains in the UFG matrix effectively impede propagation of microcracks, resulting in enhanced ductility and toughness while retaining high strength. In view of the observations collected, we propose a descriptive model for tensile deformation and fracture of bimodal UFG metals.
\end{abstract}

DOI: $10.1007 / \mathrm{s} 11661-009-0007-\mathrm{y}$

(C) The Author(s) 2009. This article is published with open access at Springerlink.com

\section{INTRODUCTION}

STRUCTURAL nanocrystalline (NC) and ultrafinegrained (UFG) metals possess remarkably high strength, but generally suffer from low ductility and toughness. ${ }^{[1,2]}$ The deterioration of ductility and toughness presently limits the use of UFG metals in manufacturing bulk mechanical parts. This is a major barrier to the widespread use of these materials.

In an effort to enhance the ductility and toughness of bulk UFG metals, incorporating coarser grains (CGs) in a UFG matrix has been suggested as a means of overcoming the observed brittle behavior. ${ }^{[3-6]}$ The motivation was based on the hypothesis that if a small proportion of CG material was added to the UFG matrix, the ductility could be increased with only a small decrement in strength analogous to ductile-phase toughening. Thus, as a simplest case, a bimodal grain size distribution, encompassing both NC and UFG regimes, has been pursued in an attempt to exploit the

ZONGHOON LEE, Staff Member, and VELIMIR RADMILOVIC, Staff Scientist, are with the NCEM, Lawrence Berkeley National Laboratory, Berkeley, CA 94720. Contact e-mail: zhlee@lbl.gov BYUNGMIN AHN, Postdoctoral Researcher, and STEVEN R. NUTT, Professor, are with the Department of Materials Science, University of Southern California, Los Angeles, CA 90089. ENRIQUE J. LAVERNIA, Provost and Executive Vice Chancellor, is with the Department of Chemical Engineering and Materials Science, University of California, Davis, CA 95616.

This article is based on a presentation given in the symposium entitled "Mechanical Behavior of Nanostructured Materials," which occurred during the TMS Spring Meeting in San Francisco, CA, February 15-19, 2009, under the auspices of TMS, the TMS Electronic, Magnetic, and Photonic Materials Division, the TMS Materials Processing and Manufacturing Division, the TMS Structural Materials Division, the TMS Nanomechanical Materials Behavior Committee, the TMS Chemistry and Physics of Materials Committee, and the TMS/ASM Mechanical Behavior of Materials Committee.

Article published online October 6, 2009 advantages of both increased strength resulting from grain refinement and retention of substantial ductility resulting from incorporation of ductile CG.

In one recent study, high tensile ductility was achieved in annealed $\mathrm{NC} \mathrm{Cu}$ with a bimodal grain size in the $\mathrm{NC}$ regime. ${ }^{[5]}$ In an earlier study of UFG alloys, Tellkamp et al. reported tensile elongation of over 8 pet in a cryomilled bulk Al alloy without significant loss of strength. ${ }^{[4]}$ The authors suggested that the presence of CG material in the NC or UFG matrix might be responsible for the enhanced ductility. Building on this early work on cryomilled Al alloys, Witkin et al. demonstrated a more feasible method to achieve a bulk bimodal microstructure from cryomilled powder by design. ${ }^{[7]}$ The deliberate blending of unmilled $\mathrm{CG}$ powders and cryomilled NC/UFG powders resulted in a bimodal grain structure comprised of a hard UFG matrix with ductile CG inclusions. This powder metallurgical process route to manufacture bimodal structures allows the convenient combination of constituents of different strength and ductility without the compositional differences normally associated with composite materials. Thus, a bimodal Al-7.5Mg consisting of UFG and CG constituents yields balanced mechanical properties that include enhanced yield and ultimate strength and acceptable or superior ductility and toughness compared to conventional grain-sized alloys and UFG metals only. ${ }^{[8]}$

However, the underlying deformation and fracture mechanisms associated with bulk bimodal metals, which can render them attractive for further design, have not been fully elucidated because of a lack of unambiguous evidence and direct observations in various scale ranges. ${ }^{[6,9-12]}$ The major difficulty in direct crosssectional observation of tensile fractures of UFG Al alloys stems from the sample preparation of nearfracture surfaces, which can preserve embedded voids 
and cracks, for scanning electron microscopy (SEM) and transmission electron microscopy (TEM). ${ }^{\text {6] }}$ In the present study, the surface treatment for SEM and thin foil preparation for cross-sectional TEM are facilitated by focused ion beam (FIB), which preserves embedded voids and cracks for systematic scrutiny. Cross sections of tensile fractures were examined to determine the deformation and failure mechanisms of cryomilled bulk bimodal Al-Mg alloy.

\section{EXPERIMENTAL PROCEDURES}

The bimodal Al-7.5Mg alloys were produced by mechanical blending of cryomilled UFG powders with 30 vol pet unmilled $\mathrm{CG}$ powder in an inert atmosphere to achieve a uniform distribution of unmilled powders. Experimental details on the cryomilling experiments can be found elsewhere. ${ }^{[7,9]}$ For comparison, UFG samples were prepared from 100 vol pct cryomilled powders. The powders used for cryomilling and for unmilled

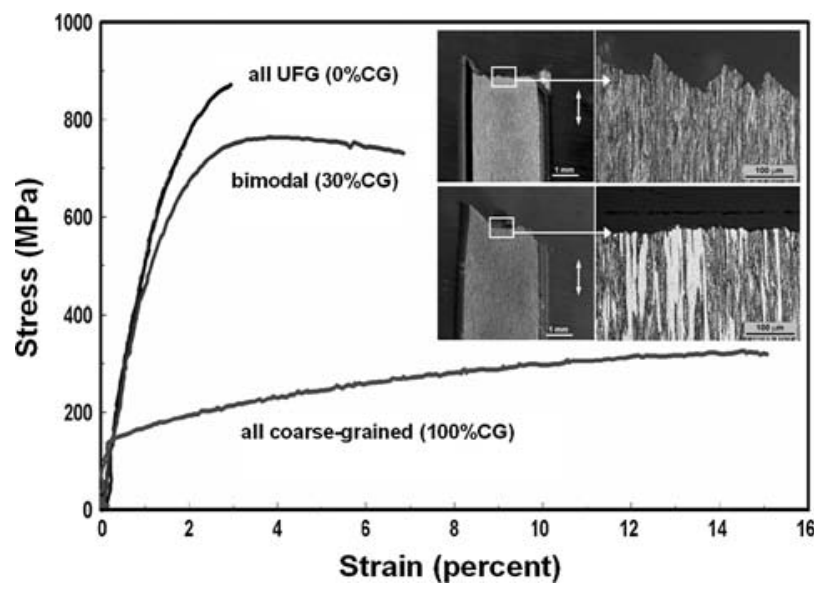

Fig. 2-Schematic of uniaxial tensile stress-strain behaviors of bimodal UFG Al alloys compared with all UFG and CG metals. Crosssectional micrographs of tensile-fractured specimens of CG0 and CG30 percent content. The CG region appears brighter by chemically etched fractures in zoomed-in images. Arrows indicate the extrusion and tensile directions.
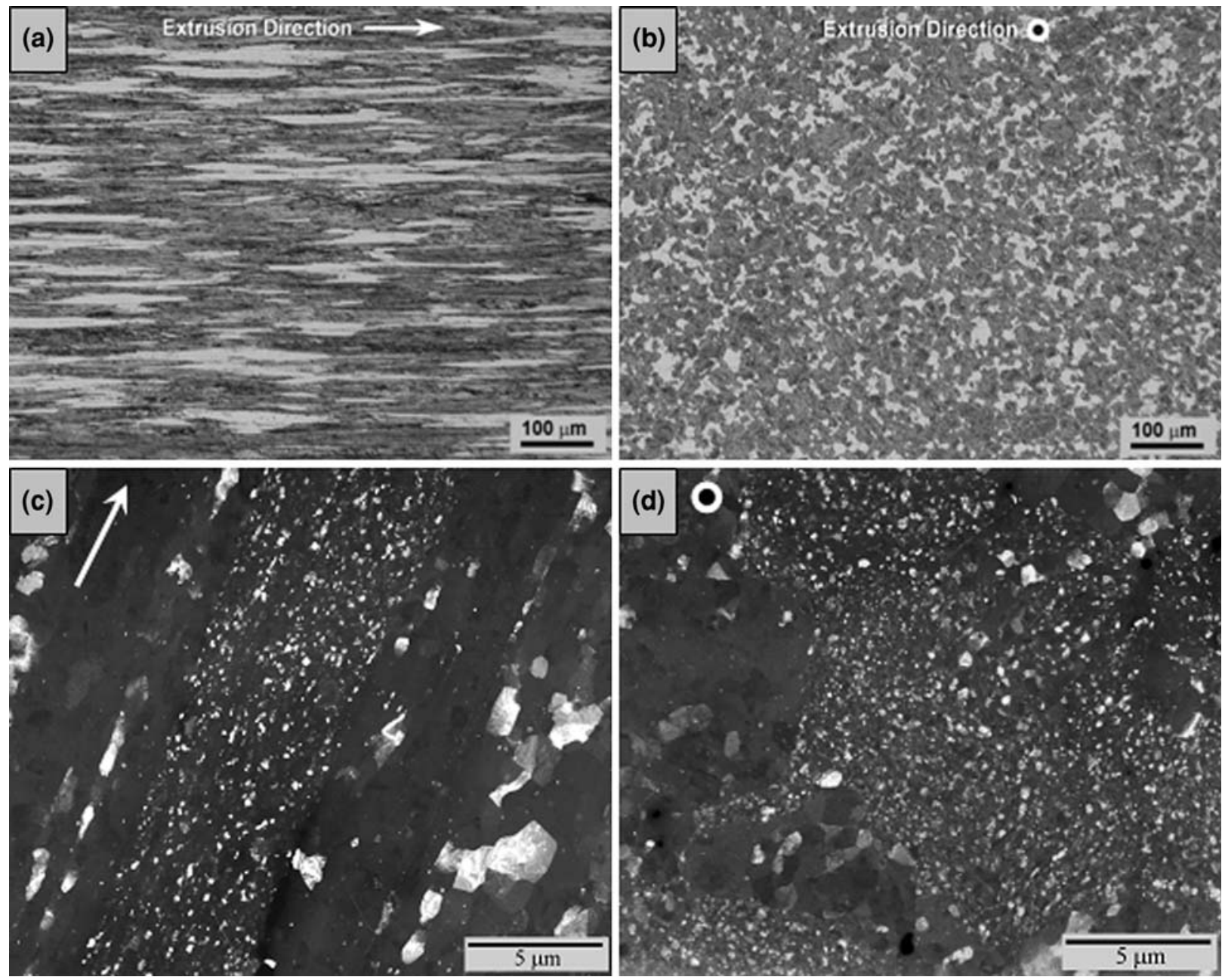

Fig. 1-Typical bimodal microstructures of as-extruded Al-Mg alloys with CG30 percent content. Optical micrographs along the (a) extrusion and $(b)$ transverse directions. The bright contrast indicates CG regions. The dark-field TEM images are shown in the $(c)$ extrusion and $(d)$ transverse directions. The CG and ultrafine grain are evident. 
additions were from the same spray-atomized batch. The powder blends were canned and then consolidated by cold isostatic pressing at a pressure of $\sim 400 \mathrm{MPa}$. The consolidated compacts were vacuum degassed at $673 \mathrm{~K}$. To remove any remaining porosity and improve mechanical properties, the consolidated billets were extruded at $823 \mathrm{~K}$ to a round bar $19.05 \mathrm{~mm}$ in diameter.

Cylindrical tensile specimens with a gage length of $13.5 \mathrm{~mm}$ and a gage diameter of $3 \mathrm{~mm}$ were tested on a universal testing machine (Instron 8801, Canton, MA). Uniaxial tensile tests were performed parallel to the extrusion direction at a constant crosshead velocity of $0.012 \mathrm{~mm} / \mathrm{s}$ until failure, with direct measurement of the displacement of the tensile gage section by a dualcamera video extensometer.

The cross sections of tensile fracture ends were molded and mechanically polished and chemically etched for optical microscopy (OM) observation. The FEI dual beam (FIB) milling on mechanically polished surfaces was used to remove surface oxide and ensure smooth surfaces for SEM observation.

The TEM specimens near tensile fracture surfaces were molded to preserve the fracture surface and cracks and then sectioned with a diamond saw. The thin and small specimens were mechanically polished to a thickness of 2 to $5 \mu \mathrm{m}$ and bonded to a half-cut TEM slotted grid for FIB milling. Areas of interest beneath fracture surfaces were thinned by FIB milling to prepare electron transparent sections for TEM observation. The TEMs (JEOL*

*JEOL is a trademark of Japan Electron Optics Ltd., Tokyo.

200CX and field emission PHILIPS** CM200)

**PHILIPS is a trademark of FEI Company, Hillsboro, OR.
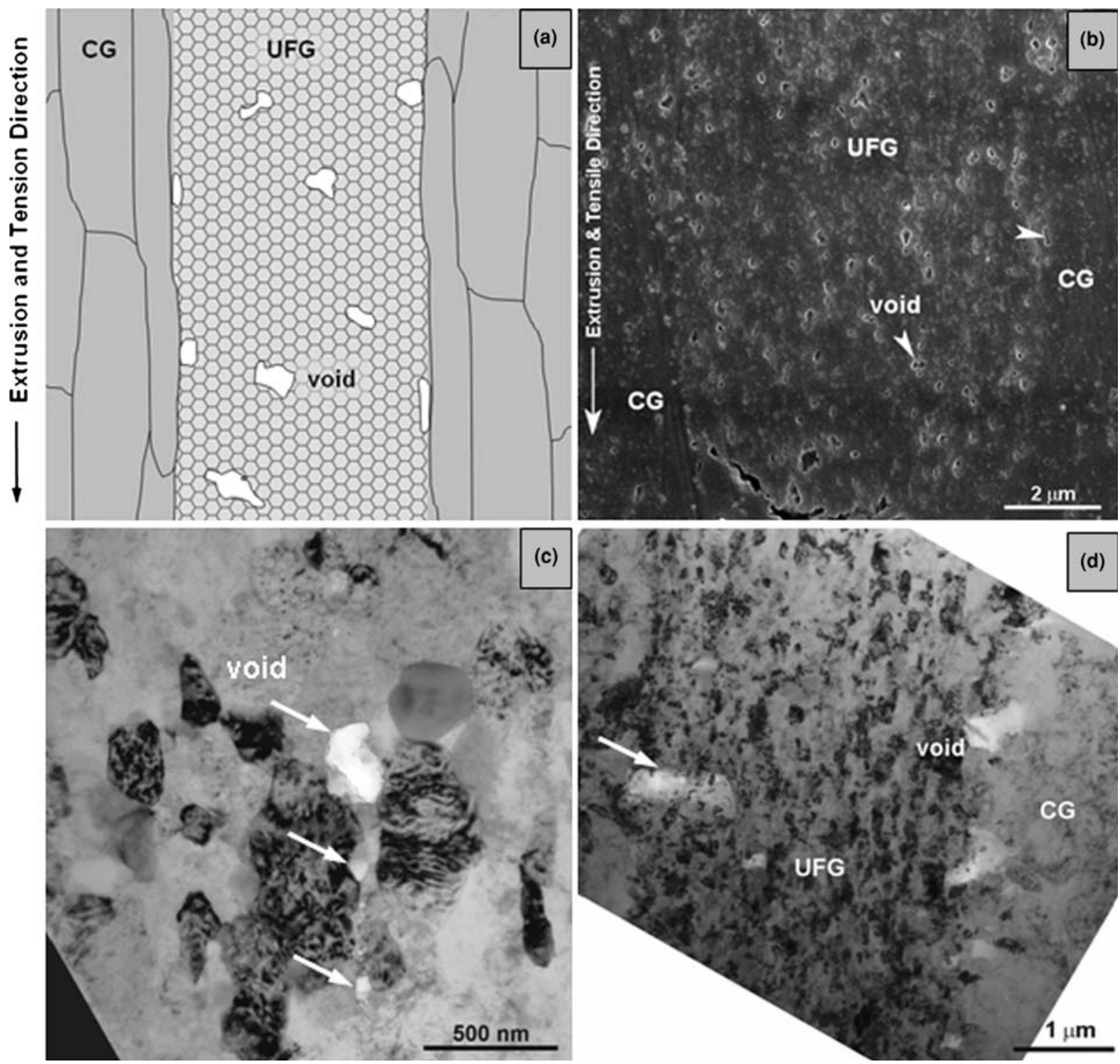

Fig. 3-Void initiation in (a) schematic, (b) SEM, and $(c)$ and (d) TEM images. The TEM samples were prepared by FIB. 
were operated at $200 \mathrm{kV}$ for bright- and dark-field imaging.

\section{RESULTS AND DISCUSSION}

The typical bimodal microstructure of as-extruded cryomilled Al- $\mathrm{Mg}$ alloy is shown in Figure 1, which shows OM images and TEM dark-field images along the extrusion and transverse directions. When chemically etched surfaces are viewed normal to the extrusion direction, UFG and CG regions exhibit dark and bright contrast, respectively. The CG regions extend along the extrusion direction and form discrete narrow bands surrounded by the continuous UFG matrix. The individual grains in both $\mathrm{CG}$ and UFG regions are evident in the TEM dark-field images. The mean grain sizes of the UFG and CG regions were estimated to be $\sim 100$ to $300 \mathrm{~nm}$ and $1 \mu \mathrm{m}$, respectively. Microhardness measurements performed on the two discrete regions indicated that the UFG region was approximately 2 times harder than the $\mathrm{CG}$ regions. ${ }^{[8]}$

Figure 2 shows an idealized experimental tensile stress-strain curve for the as-extruded bimodal alloy (30 pct CG), the all-UFG alloy (0 pct CG), and a conventional Al-Mg alloy (100 pet CG) ${ }^{[8]}$ The all-UFG sample showed a high yield strength followed by a brief period of work hardening, but the specimen failed abruptly without necking, as shown in the inset fracture end cross section. It exhibits fully flat (plain strain) fracture and involves a brittle transgranular shear type separation. No delamination cracks perpendicular to the fracture plane are observed. The bimodal $\mathrm{Al}-\mathrm{Mg}$ alloy with 30 pct $C G$ demonstrated a slightly lower strength and greater ductility, as manifested by the flow-stress plateau after the ultimate tensile strength. Necking occurs in the bimodal 30 pct CG, as shown in the inset of the figure, which indicates more ductile behavior compared to the UFG sample. The fracture surface cross section shows mixed fracture mode: large shear lips with flat central region. Note that the central region of the fracture end of the bimodal sample (30 pct CG) is much flatter than that of the UFG sample, which is jagged. The all-CG specimens exhibited about one-third the ultimate strength of the bimodal samples, but more extensive work hardening and much higher strains than either the UFG or bimodal alloys. The difference between all ultrafine grains, 30 pct CG, and all CGs in the Young's modulus calculated from the elastic portion of true stress-strain curves is marginal, as expected.

The strength and ductility values for bimodal alloys were intermediate between those of the UFG and the all-CG materials, representing a balance of both strength and ductility. This suggests that bimodal alloys have unusual deformation and fracture mechanisms arising from the fine-scale combination of hard and soft phases. The deformation and fracture mechanisms warrant further investigation, which is pursued through examination of tensile fractures.

Voids near tensile fractures of bimodal specimens tended to initiate both in UFG regions and in the interfaces between UFG and CG regions. Constrained
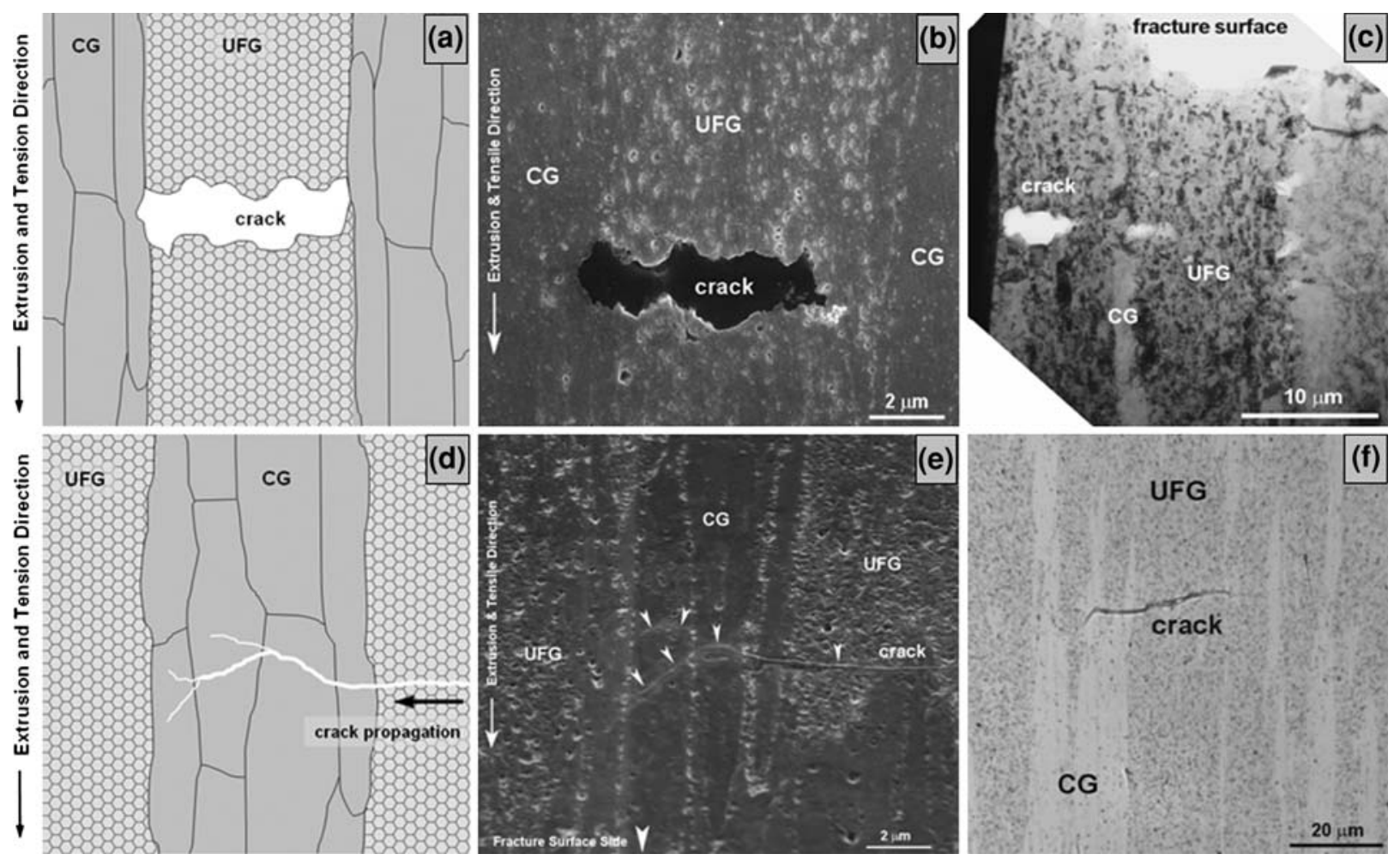

Fig. 4 - (a) through $(c)$ Schematic, SEM, and TEM micrographs of crack blunting of UFG at the CG region. $(d)$ through $(f)$ Deflecting and branching of a longitudinal crack in CG. Schematic, SEM, and optical micrographs. 
ductile $\mathrm{CG}$ regions within the UFG matrix undergo yielding prior to UFG regions during tensile loading. However, after yielding, CG regions plastically deformed without fracture while the UFG matrix carried most of the tensile load elastically. ${ }^{[10]}$ In contrast, UFG regions plastically deformed very briefly after yielding at a higher stress, because dislocation multiplication over short distances was effectively limited under sufficiently high applied stresses. In terms of load transfer, UFG regions sustained most of the applied stress and only a small part of the load was transferred to the softer $\mathrm{CG}$ regions. This phenomenon is analogous to load transfer in fiber-reinforced composites, although in the present case, the stronger phase is continuous. This causes a slight decrease in yield strength of the bimodal specimen. Subsequent to yielding of the UFG matrix, stress concentrations in the UFG regions may be relaxed by void generation and growth and by transferring local loads to the softer $\mathrm{CG}$ regions. In addition, stress mismatch between $\mathrm{CG}$ and ultrafine grains also increases with the increase of quasi-static load ${ }^{[10,11]}$ and leads to initiation of voids at the UFG-CG interface, as illustrated in the schematic of Figure 3(a). Voids are observed both in the UFG matrix and at the UFG-CG interfaces near fracture surfaces, as shown in Figure 3(b). Fine voids did not appear in the SEM. However, TEM observations (Figure 3(c)) revealed small voids about 50 to $300 \mathrm{~nm}$, similar to the grain size of UFG regions. The cross-sectional TEM sample in Figure 3(d), which was prepared by FIB, shows the preserved voids located in the CG and UFG interfaces.

Cracks were also evident in the UFG matrix between $\mathrm{CG}$ bands, and several cracks were apparently arrested by the ductile $\mathrm{CG}$ bands. Crack propagation in UFG regions tended to stop at $\mathrm{CG}$ regions, and interface voids appeared to coalesce by transgranular-shear type separation and remain in the UFG regions. Ductile CG
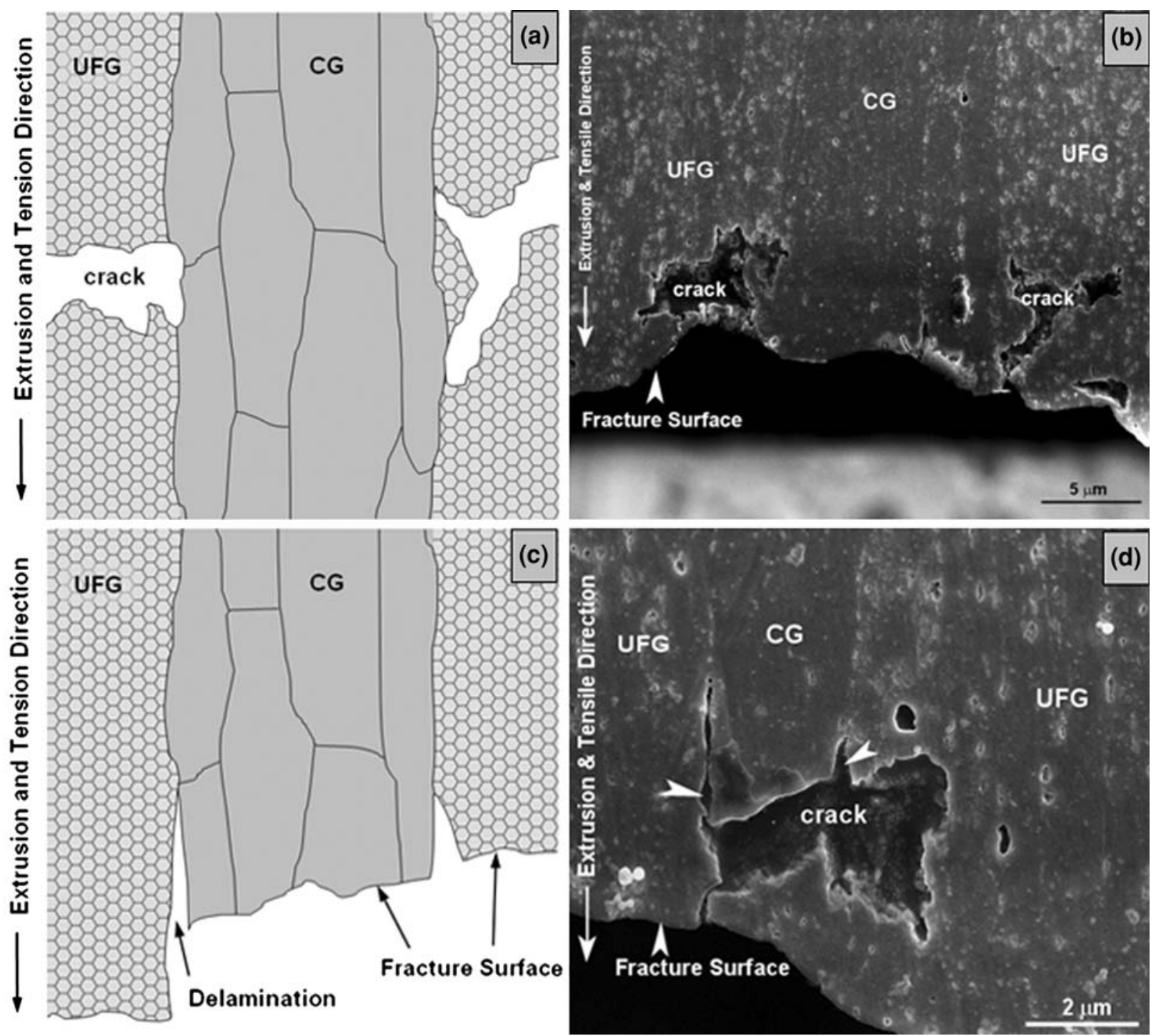

Fig. 5- $(a)$ and (b) Schematic and SEM images of crack bridging and branching of CG. $(c)$ and $(d)$ Interface delaminating and extensive plastic deformation of CG. 

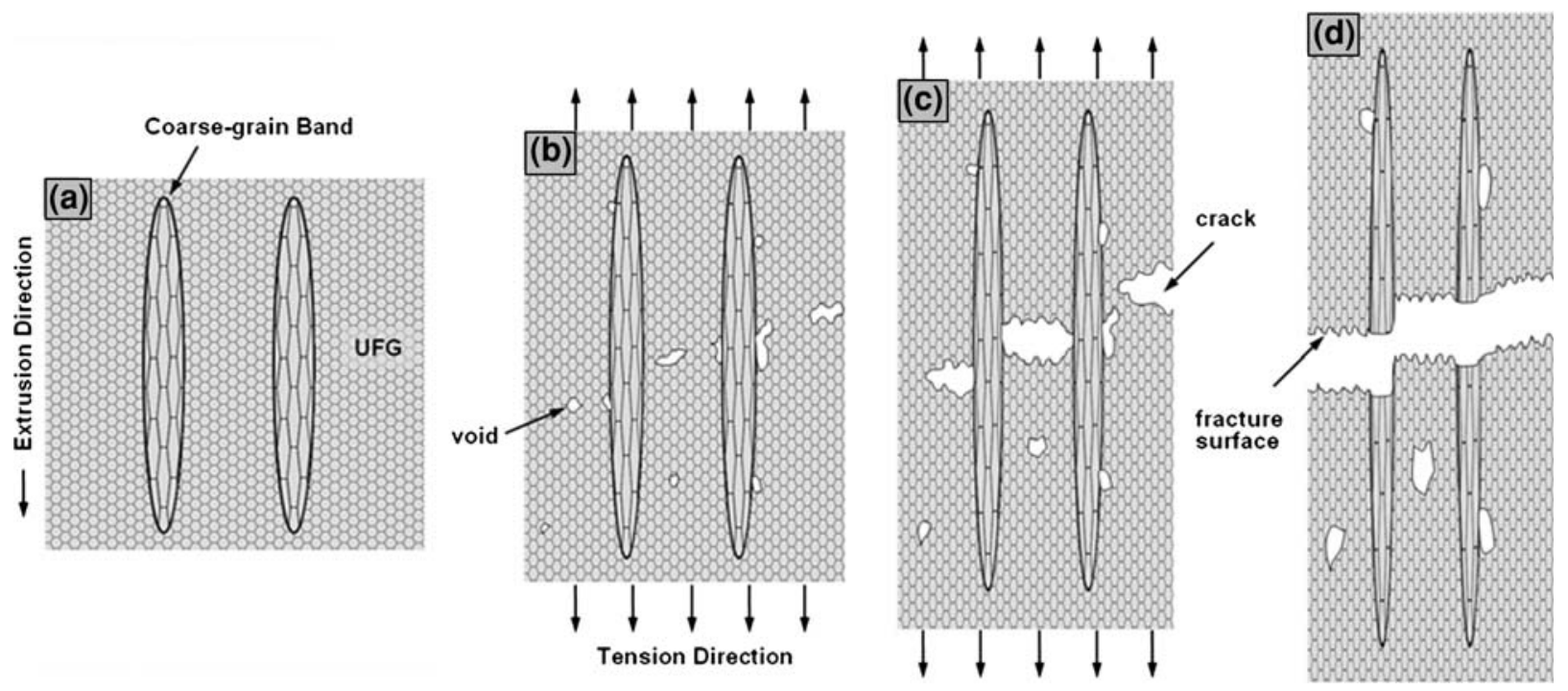

Fig. 6-Schematic of tensile deformation and fracture mechanism of bimodal UFG Al-Mg alloys under uniaxial tension along the extrusion direction: $(a)$ as extruded, $(b)$ void nucleation and growth, $(c)$ crack growth, and $(d)$ fracture.

regions may sustain additional plastic deformation beyond yielding of the UFG matrix, which is the majority constituent by volume. Thus, ductile CG bands effectively blunt propagating crack tips. Figures 4(a) and (b) show a schematic of the crack blunting together with an SEM image of a similarly blunted crack in a UFG region between two CG bands. A similar configuration is shown in the TEM image of Figure 4(c), which reveals blunted cracks in UFG regions, as well as voids. These observations indicate that despite the thin and relatively small volume fraction of CG bands, they effectively inhibit and delay tensile fracture in bimodal specimens. Additional crack configurations are illustrated in Figures 4(d) through (f). Figure 4(d) shows a schematic of a crack that grew into a CG region, branched, and then stopped. A similar crack configuration was observed in the SEM, as shown in Figure 4(e), while an unbranched crack was observed in halt in a CG region, as shown in Figure 4(f).

Figure 5 illustrates by a schematic drawing a process by which CG bands can bridge cracks and inhibit abrupt fracture. Cracks tend to initiate within UFG regions, while CG regions tend to constrain their growth (Figure 5(a)). This is effectively a ductile-phase toughening mechanism, and such bimodal microstructures can be designed as optimized for structural applications. ${ }^{[13-15]}$ Note also that interface delamination between CG and UFG regions perpendicular to the fracture plane is evident in Figures 5(c) and (d). These are regions of severe plastic deformation near tensile fractures, and such delaminations may contribute to the enhanced ductility in bimodal specimen.

In view of observations collected, we propose a descriptive model for tensile deformation and fracture of bimodal UFG metals, as shown in Figure 6. The tensile deformation and fracture stage are described by the four steps in the schematic. First, the CG regions are elongated along the extrusion direction in the as-extruded specimen (Figure 6(a)), and uniaxial tension is applied to the specimen along the extrusion direction. When the stress reaches the yield point of the CG material, plastic deformation occurs within these regions. Second, as the stress increases and reaches the yield point of UFG material, voids initiate within UFG regions and at UFG-CG interfaces, and the CG bands undergo elongation, as shown in Figure 6(b). Third, as the tensile strain increases, cracks grow from the voids and extend transverse to the load axis. However, the cracks tend to be localized in UFG regions between CG regions, as shown in Figure 6(c). Cracks are effectively impeded by the CG stringers, which blunt and bridge the cracks, causing, in some cases, deflection and branching in CG regions and at UFG-CG interfaces. Finally, fracture ensues when cracks link and the CG regions can no longer sustain the load, as shown in Figure 6(d).

\section{CONCLUSIONS}

Direct observations in various scale ranges revealed void nucleation and crack behavior in tensile fracture of bimodal Al-Mg alloys. The bimodal grain structures exhibited unusual deformation and fracture mechanisms similar to ductile-phase toughening of brittle materials. Voids initiated and grew in the UFG matrix and at CG-UFG interfaces. The CG bands tended to deform locally at stress concentrations, arresting cracks by local blunting, resisting crack growth by bridging of crack wakes, and impeding crack propagation by deflecting and branching of crack tips and by delamination during plastic deformation.

The present work provides insights for the design of UFG metals resistant to deformation and fracture. Using these observations, single-phase materials with 
local variations in grain size can be designed to achieve unique combinations of strength, ductility, and toughness. Using this design approach, the deformation mechanisms can be altered by manipulating (a) the morphology and dispersion of the CG phase and (b) the interface properties and by selecting the intrinsic mechanical properties of phases. Single-phase, composite-like materials, because of the perfect CTE match of the constituent phases, may be well suited to hightemperature applications and processing routes. Further work is warranted to optimize bimodal microstructures for mechanical performance and to extend the approach to different multiscale alloys. ${ }^{[16]}$ Dynamic straining experiments employing in-situ observation techniques should provide further insights into deformation and fracture mechanisms of bimodal materials.

\section{ACKNOWLEDGMENTS}

Support from the Office of Naval Research (Contract Nos. ONR00014-03-1-0149 and ONR0001403-C-0163) is gratefully acknowledged. The National Center for Electron Microscopy is supported by the Director, Office of Science, United States Department of Energy, under Contract No. DE-AC02-05C H11231.

\section{OPEN ACCESS}

This article is distributed under the terms of the Creative Commons Attribution Noncommercial
License which permits any noncommercial use, distribution, and reproduction in any medium, provided the original author(s) and source are credited.

\section{REFERENCES}

1. R.W. Siegel and G.E. Fougere: Nanostruct. Mater., 1995, vol. 6, pp. 205-16.

2. C.C. Koch, D.G. Morris, K. Lu, and A. Inoue: MRS Bull., 1999, vol. 24 (2), pp. 54-58.

3. M. Legros, B.R. Elliot, M.N. Rittner, J.R. Weertman, and K.J. Hemker: Phil. Mag. A, 2000, vol. 80 (4), pp. 1017-26.

4. V.L. Tellkamp, A. Melmed, and E.J. Lavernia: Metall. Mater. Trans. A, 2001, vol. 32A, pp. 2335-43.

5. Y.M. Wang, M.W. Chen, F.H. Zhou, and E. Ma: Nature, 2002, vol. 419 , pp. 912-15.

6. Z. Lee, R. Rodriguez, R.W. Hayes, E.J. Lavernia, and S.R. Nutt: Metall. Mater. Trans. A, 2003, vol. 34A, pp. 1473-81.

7. D. Witkin, Z. Lee, R. Rodriguez, S.R. Nutt, and E.J. Lavernia: Scripta Mater., 2003, vol. 49, pp. 297-302.

8. Z. Lee, D. Witkin, V. Radmilovic, E.J. Lavernia, and S.R. Nutt: Mater. Sci. Eng. A, 2005, vols. 410-411, pp. 462-67.

9. B.Q. Han, Z. Lee, D. Witkin, S.R. Nutt, and E.J. Lavernia: Metall. Mater. Trans. A, 2005, vol. 36A, pp. 957-65.

10. Z. Lee, J. Lee, E.J. Lavernia, and S.R. Nutt: MRS Symp. Proc. 821, Nanoscale Materials and Modeling-Relations Among Processing, Microstructure and Mechanical Properties, P.M. Anderson, T. Foecke, A. Misra, and R.E. Rudd, eds., Pittsburgh, PA, 2004, pp. 9.11.1-9.11.6.

11. R.Q. Ye, B.Q. Han, and E.J. Lavernia: Metall. Mater. Trans. A, 2005, vol. 36A, pp. 1833-40.

12. G.J. Fan, H. Choo, P.K. Liaw, and E.J. Lavernia: Acta Mater., 2006, vol. 54, pp. 1759-66.

13. L.S. Sigl, P.A. Mataga, B.J. Dalgleish, R.M. McMeeking, and A.G. Evans: Acta Metall., 1988, vol. 36, pp. 945-53.

14. P.A. Mataga: Acta Metall., 1989, vol. 37, pp. 3349-59.

15. M.F. Ashby, F.J. Blunt, and M. Bannister: Acta Metall., 1989, vol. 37, pp. 1847-57.

16. J. Ye, B.Q. Han, Z. Lee, B. Ahn, S.R. Nutt, and J.M. Schoenung: Scripta Mater., 2005, vol. 53, pp. 481-86. 